\title{
Coupling Pd-Catalyzed Alcohol Oxidation to Olefin Functionalization: Hydrohalogenation/Hydroalkoxylation of Styrenes
}

\author{
Susanne M. Podhajsky and Matthew S. Sigman ${ }^{*}$ \\ Department of Chemistry, University of Utah, 315 South, 1400 East, Salt Lake City, Utah 84112
}

\begin{abstract}
A hydrochlorination reaction of styrenes catalyzed by $\mathrm{Pd}^{\mathrm{II}}$ in combination with $\mathrm{Cu}^{\mathrm{II}}$ was developed, which was followed by an in situ conversion of electron-rich products to an ether in the presence of an alcohol. Mechanistic experiments indicate that olefin functionalization is coupled to an alcohol oxidation, wherein a Pd hydride formed in the $\beta$-hydride elimination step of the alcohol oxidation was incorporated into the product.
\end{abstract}

\section{Introduction}

Carbon-oxygen and carbon-halogen bonds are prevalent in organic compounds, and thus, a number of methods exist to achieve their formation. ${ }^{1}$ One of the classic ways to form C-O and $\mathrm{C}-\mathrm{X}$ bonds is the addition of HX or HOR to double bonds, which is typically an acid-catalyzed reaction. ${ }^{1}$ Unfortunately, strong acids are often required and do not always lead to high product yields. ${ }^{2}$ To overcome these disadvantages, hydrohalogenation reactions have been developed, where a small amount of acid is formed in situ, thus lowering the concentration of strong acid and providing milder reaction conditions. ${ }^{3}$ However, to the best of our knowledge, acid catalysis remains the only route used for the addition of HX across alkenes (Figure 1A).

A seemingly different approach has been taken with hydroalkoxylation reactions using metal catalysis. Most of these reactions have been proposed to occur via oxymetallation of the substrate followed by protonation of the resulting metal-carbon bond to regenerate the catalyst (Figure 1B). ${ }^{4,5}$ These transformations are especially well-known for alkenes adjacent to an electron withdrawing group, ${ }^{4 i, j}$ but some have also been developed for nonactivated alkenes. Interestingly, most metal catalysts capable of reacting with nonactivated alkenes require triflate counterions, ${ }^{4 \mathrm{a}-\mathrm{g}}$ and Hartwig and co-workers have recently shown that, in at least some of these systems, TfOH is formed in situ, which then acts as the active catalyst. ${ }^{6 a}$ Thus, the character of the active catalyst in a number of hydroalkoxylation reactions is questionable, and these reactions possibly proceed via an acid-catalyzed mechanism analogous to that of hydrohalogenation. ${ }^{5}$

Because of the use of rather strong acids in most hydrohalogenation and hydroalkoxylation reactions, poor functional group tolerance is often displayed, ${ }^{7}$ and it thus seems desirable to develop metal-catalyzed variants, which could possibly overcome this disadvantage. In our

(C) 2007 American Chemical Society

* Corresponding author. E-mail: sigman@chem.utah.edu..

Supporting Information Available: Experimental procedures, details for isotopic labeling experiments, and characterization data for substances. This material is available free of charge via the Internet at http://pubs.acs.org. 
laboratory, a hydroalkoxylation of vinylphenols has recently been discovered (eq 1), which is believed to proceed through a mechanism distinct from previously reported hydroalkoxylation reactions. ${ }^{8}$ This reaction was originally thought to proceed via the oxymetallation/protonation mechanism (Figure 1). To test this, the reaction was performed in $\mathrm{CH}_{3} \mathrm{CH}_{2} \mathrm{OD}$, which should result in the incorporation of a single deuterium atom. ${ }^{8 \mathrm{a}}$ However, analysis of the
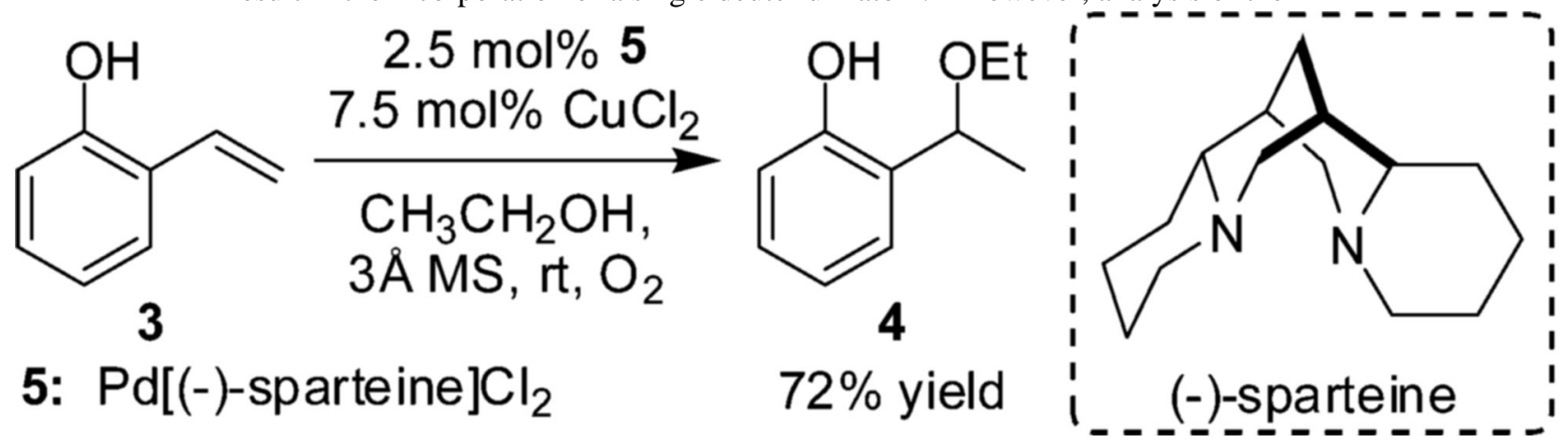

product revealed no deuterium incorporation (Scheme 1). Only when the reaction was carried out in $\mathrm{CD}_{3} \mathrm{CD}_{2} \mathrm{OD}$ was the incorporation of one $\mathrm{D}$ into the side chain observed (Scheme 1). On the basis of these findings, the reaction is proposed to occur via insertion of an alkene into a Pd hydride $\mathbf{C}$, which is formed via Pd-catalyzed aerobic oxidation of the alcoholic solvent and thus stems from the alkyl chain of the alcohol (Figure 2A). ${ }^{9,10}$ This insertion reversibly forms Pd alkyl complexes $\mathbf{E}$ and $\mathbf{F}$, of which $\mathbf{F}$ can proceed to form quinone methide intermediate G. This quinone methide undergoes nucleophilic attack to form the hydroalkoxylation product 4 . The reversible formation of both $\mathbf{E}$ and $\mathbf{F}$ is proposed based on the observation of $\mathbf{6 a}$ and $\mathbf{6 b}$ in the isotopic labeling experiments (Scheme 1). ${ }^{8 \mathrm{a}}$

Although $o$ - or $p$-vinylphenols are required in this reaction to access the quinone methide intermediate, we hypothesized that simple styrenes could undergo a similar reaction via a slightly different pathway (Figure 2B). In this paper, we describe the development of an alcohol oxidation coupled hydroalkoxylation of styrenes and several mechanistic experiments to probe the fundamental aspects of the reaction, which revealed that while an overall hydroalkoxylation reaction occurred, it proceeded via an unexpected benzylic chloride intermediate.

\section{Results and Discussion}

\section{Reaction Development}

As an initial experiment, the hydroalkoxylation of 4-methylstyrene was tested using conditions similar to those developed for vinyl phenols. It had been found previously that submitting simple styrene substrates to similar reaction conditions in an $\mathrm{EtOH}$ solvent led to acetal products, ${ }^{11}$ and therefore, $i \mathrm{PrOH}$, a much less nucleophilic alcohol that readily undergoes oxidation, ${ }^{12}$ was selected as a solvent. Initially, 4-methylstyrene (7a) was chosen as the substrate, using $\mathrm{Pd}[(-)$-sparteine $] \mathrm{Cl}_{2}$ and $\mathrm{CuCl}_{2}$ in $i \mathrm{PrOH}$ at $40{ }^{\circ} \mathrm{C}$. Under these conditions, the desired hydroalkoxylation product was observed as the minor product, with the major product arising from Wacker oxidation (Scheme 2). Gratifyingly, the hydroalkoxylation product 8a formed as a single regioisomer, which can be rationalized with the stabilization of $\mathbf{L}$ (as compared to $\mathbf{K}$; see Figure $2 \mathrm{~B}$ ) via a $\pi$-benzyl Pd complex. ${ }^{13}$

With this initial result in hand, control experiments were performed, omitting either $\mathrm{Pd}$ or $\mathrm{Cu}$ to verify that both metals were required (Table 1, entries 2 and 3). Subsequently, the reaction conditions were optimized for the hydroalkoxylation product, the first steps of which are shown in Table 1. We hypothesized that the Wacker product likely arose from $\mathrm{H}_{2} \mathrm{O}_{2}$, which is formed as a byproduct of aerobic alcohol oxidation. ${ }^{14}$ Therefore, it was thought that the rate of alcohol 
oxidation should be decreased to obtain high selectivities for the hydroalkoxylation product, so that ideally, every Pd hydride formed is incorporated into product. While the rate of alcohol oxidation could be decreased by lowering the concentration of the alcohol, $i \mathrm{PrOH}$ was also thought to be acting as the nucleophile, and lowering its concentration could potentially decrease the selectivity for the hydroalkoxylation product. Testing several different concentrations of $i \mathrm{PrOH}$ in 1,2-dichloroethane (DCE), 60\% $i \mathrm{PrOH}$ in DCE was found to give the highest yield of hydroalkoxylation product (33\%, Table 1, entry 4). Lowering the substrate concentration from 0.1 to $0.05 \mathrm{M}$, thus increasing the catalyst loading with respect to the substrate, led to an additional improvement (46\%, Table 1, entry 5).

Further variation of the reaction conditions unfortunately did not lead to improvement in the reaction outcome. We therefore decided to evaluate other ligands on $\mathrm{PdCl}_{2}$ and found that bathocuproine (2,9-dimethyl-4,7-diphenyl-1,10-phenanthroline, bc) dramatically increased the reaction rate. However, when a time course of the reaction was performed by GC sampling, a significant induction period was observed (Figure 3, $\mathbf{\Delta}$ ).${ }^{15}$ Bathocuproine is known to be a ligand for both $\mathrm{Pd}$ and $\mathrm{Cu},{ }^{12 \mathrm{a}}, 16$ and thus, it was hypothesized that bathocuproine could be dissociating from the Pd complex during that induction period, with ligand-less Pd acting as the active catalyst. A separate time course was performed with preformed $\mathrm{Cu}(\mathrm{bc}) \mathrm{Cl}_{2}$ rather than $\mathrm{Pd}(\mathrm{bc}) \mathrm{Cl}_{2}$, mimicking the hypothesized catalyst mixture present after the induction period (Figure 3, ०). Upon performing the experiment, no induction period was observed when bathocuproine was bound to $\mathrm{Cu}$ instead of $\mathrm{Pd}$ prior to the start of the reaction. As a control, the reaction was performed with $\mathrm{Pd}-(\mathrm{MeCN})_{2} \mathrm{Cl}_{2}$ and $\mathrm{CuCl}_{2}$ as well as with $\mathrm{Pd}(\mathrm{bc}) \mathrm{Cl}_{2}$ and $\mathrm{Cu}$ (bc)- $\mathrm{Cl}_{2}$. The latter reaction displayed a lower selectivity for the hydroalkoxylation product, while using ligand-less conditions led to decreased selectivity as well as a decreased reaction rate. ${ }^{17}$ From these experiments, it was concluded that improved selectivity and reaction rates were observed with a ligand on $\mathrm{Cu}$ rather than $\mathrm{Pd}$, indicating that $\mathrm{Cu}$ was likely playing a more complex role than simply reoxidizing $\mathrm{Pd}^{0}$ to $\mathrm{Pd}^{\mathrm{II}}$, as is commonly proposed in Wacker-type oxidations. ${ }^{18}$

Additionally, upon switching to bathocuproine, a careful analysis of the reaction mixture showed the presence of an intermediate (Figure 4, $\boldsymbol{\Delta}$ ), which was identified as the benzylic chloride 10a. On the basis of this observation, it was concluded that the active nucleophile is a chloride ion rather than $i \mathrm{PrOH}$ and that the hydroalkoxylation product likely arises from the benzylic chloride via an $\mathrm{S}_{\mathrm{N}} 1$-type mechanism (vide infra). Considering that there is 4 times more $\mathrm{CuCl}_{2}$ in the reaction mixture than $\mathrm{PdCl}_{2}$, it is likely that $\mathrm{CuCl}_{2}$ is the major source for that chloride. Overall, this is an interesting and unexpected finding since metal-catalyzed hydrochlorination reactions have not been observed previously.

Having gained some crucial insight into the reaction from the experiments detailed previously, further optimization was performed using $\mathrm{Pd}(\mathrm{MeCN})_{2} \mathrm{Cl}_{2}$ and a mixture of $\mathrm{Cu}(\mathrm{bc}) \mathrm{Cl}_{2}$ and $\mathrm{CuCl}_{2}$. Interestingly, a combination of $10 \mathrm{~mol} \% \mathrm{Cu}(\mathrm{bc}) \mathrm{Cl}_{2}$ with $30 \mathrm{~mol} \% \mathrm{CuCl}_{2}$ was optimal, giving a 47\% GC yield of the hydroalkoxylation product (Table 2, entry 2), while $40 \mathrm{~mol} \%$ $\mathrm{Cu}(\mathrm{bc}) \mathrm{Cl}_{2}$ gave $15 \%$ hydroalkoxylation and $51 \%$ Wacker product (Table 2, entry 1). Assuming that the chloride intermediate (10) was converted to product via an $\mathrm{S}_{\mathrm{N}} 1$-type reaction, the rate of this substitution should be independent of the concentration of $i \mathrm{PrOH}$ (apart from polarity effects), and $i \mathrm{PrOH}$ should influence the reaction mainly via the rate of alcohol oxidation (vide supra). When the concentration of $i \mathrm{PrOH}$ was further lowered to $10 \% i \mathrm{PrOH}$ in DCE, the selectivity for the hydroalkoxylation product improved slightly to 49\% GC yield (Table 2, entry 3). Subsequently, the temperature was raised to accelerate the nucleophilic substitution. This, in turn, would release more chloride and thus promote the formation of benzylic chloride 10. Indeed, when the temperature was increased from 40 to $60{ }^{\circ} \mathrm{C}$, the $\mathrm{GC}$ yield of the hydroalkoxylation product increased to $62 \%$ (Table 2, entry 4). Additionally, the amount of chloride in the reaction mixture was further raised by changing the loading of $\mathrm{CuCl}_{2}$ from 30 
to $40 \mathrm{~mol} \%$, leading to $84 \%$ GC yield of the desired product (Table 2, entry 5). Higher concentrations of $\mathrm{CuCl}_{2}$ unfortunately inhibited the reaction, presumably due to slowing the rate of alcohol oxidation. ${ }^{19}$ Under these conditions, the catalyst loading could be reduced without substantial decrease in product yield (77\% GC yield, Table 2, entry 6).

Having optimized the reaction for 4-methylstyrene, several other substrates were submitted to the reaction conditions. While electron-rich styrenes are excellent substrates, electron-poor styrenes gave mixtures of hydroalkoxylation and hydrohalogenation products along with increased amounts of Wacker products, illustrating the high sensitivity of the reaction to the electronic nature of the substrate. Interestingly, while 4-methylstyrene gave good yields of the hydroalkoxylation product, styrene was sufficiently electron-poor to yield the

hydrochlorination product. For electron-poor substrates, the reaction was thus optimized for hydrochlorination by lowering the temperature to $50{ }^{\circ} \mathrm{C}$, increasing the catalyst loading to the previous level (with $50 \mathrm{~mol} \% \mathrm{CuCl}_{2}$ ), and decreasing the amount of $i \mathrm{PrOH}$ to $2.5 \%$ in DCE. Upon isolation, the hydrochlorination product was found to contain ca. $5 \%$ of the regioisomeric primary chloride (2-chloroethylarene), which was likely formed from the regioisomeric $\mathrm{Pd}$ alkyl complex (K, see Figure 1). This was entirely unexpected since no primary ether product had been observed with the electron-rich substrates. It is reasonable, however, that the primary chloride is reversibly formed in the reaction of electron-rich substrates but does not undergo the $\mathrm{S}_{\mathrm{N}} 1$ reaction to produce the ether product. ${ }^{20}$

\section{Mechanistic Investigations. Conversion of Benzylic Chloride}

The unexpected results obtained above prompted us to study the reaction in greater detail. Specifically, we wished to address the conversion of the benzylic chloride $\mathbf{1 0}$ to the ether, the roles of the different metals, and finally the origin of the proton incorporated into the product. To confirm that chloride $\mathbf{1 0}$ converted to the hydroalkoxylation product, 10a was independently prepared and submitted to reaction conditions. Indeed, when $10 \mathrm{a}$ was heated to $40^{\circ} \mathrm{C}$ in $i \mathrm{PrOH}$, it converted exclusively to the hydroalkoxylation product (8a). In the presence of metal catalysts, the reaction was significantly accelerated, possibly due to the metals acting as Lewis acid catalysts (Table 4). This information together with the fact that electron-poor benzylic chlorides do not convert completely to the ether product implies that a metal assisted $\mathrm{S}_{\mathrm{N}} 1$ reaction is most likely occurring. ${ }^{22}$

\section{Deuterium Labeling Studies}

To determine the origin of the proton incorporated into the product, several deuterium labeling experiments were performed. On the basis of precedents from our laboratory, ${ }^{8 \mathrm{a}}$ our initial hypothesis was that a Pd hydride was formed during $i \mathrm{PrOH}$ oxidation and that this hydride was subsequently incorporated into the product (vide supra). To confirm this, several deuterium labeling experiments were carried out, as shown in Figure 5.

Initially, two control experiments were performed in $\left(\mathrm{CH}_{3}\right)_{2}-\mathrm{CHOD}$ and DCE- $d_{4}$ (Figure 5, eqs 4 and 5), to probe the involvement of the acidic proton or protons from the DCE solvent. As expected, no deuterium incorporation was observed in any of the products, thus strongly suggesting the absence of Brønsted acid catalysis. Subsequently, the reaction was performed in $\left(\mathrm{CH}_{3}\right)_{2} \mathrm{CDOH}$ and $\left(\mathrm{CD}_{3}\right)_{2} \mathrm{CDOD}$, respectively (eqs 6 and 7$)$. With both of these alcohols, deuterium incorporation into the double bond was expected since the Pd hydride would be formed in the $\beta$-hydride elimination step of the alcohol oxidation and thus would stem from the $\alpha$-position of $i \mathrm{PrOH} .{ }^{9}$ However, isotopic depletion could potentially occur via the enol form of acetone (the oxidation product of $i \mathrm{PrOH})$ in the case of $\left(\mathrm{CH}_{3}\right)_{2} \mathrm{CDOH}$. With $\left(\mathrm{CD}_{3}\right)_{2} \mathrm{CDOD}$, any such exchange would be inconsequential. ${ }^{23}$ Upon performing these experiments, very similar results were observed, in which two main isotopologues are formed. The major isotopologue containing 2 or $8 \mathrm{D}$, respectively, is consistent with the proton incorporated into 
the side chain arising from alcohol oxidation and is formed in 48 and $46 \%$ yield (of the overall hydroalkoxylation product). However, another isotopologue with 1 (or 7) D was observed in 39 and $43 \%$ yield, which was initially unexpected. Closer investigation of the styrene substrate at early time points revealed partial $\mathrm{D}$ incorporation, and an isotopologue containing 3 or $9 \mathrm{D}$ was observed in $11 \%$. This D incorporation into substrate could arise from reversible alkene insertion/ $\beta$-hydride elimination (Scheme 3 ) and provides a pathway for D scrambling and potential isotopic depletion in the product. ${ }^{24}$

To probe this, substrate 15 was prepared containing $3 \mathrm{D}$ in the olefin (93\% $3 \mathrm{D})$ and submitted to reaction conditions with $\left(\mathrm{CH}_{3}\right)_{2} \mathrm{CDOH}$ or $\left(\mathrm{CD}_{3}\right)_{2} \mathrm{CDOD}$ (eqs 8 and 9). As expected, significantly higher levels of isotopic incorporation were observed, consistent with the equilibrium shown previously. Specifically, the major isotopologue (containing 5 and $11 \mathrm{D}$, respectively) was formed in 74 and $81 \%$, again indicating that no significant exchange via enol chemistry was occurring.

Additionally, it was found that the reaction using deuterated substrate 15 in $\left(\mathrm{CH}_{3}\right)_{2} \mathrm{CDOH}$ or $\left(\mathrm{CD}_{3}\right)_{2} \mathrm{CDOD}$ was significantly faster than that using nonlabeled material (15 in $\left(\mathrm{CH}_{3}\right)_{2} \mathrm{CDOH}$ : $43 \%$ conversion at $0.5 \mathrm{~h} ; \mathbf{7 a}$ in $i \mathrm{PrOH}$ : $18 \%$ conversion at $0.5 \mathrm{~h}$ ), indicating a large inverse isotope effect. ${ }^{17}$ This unusual finding indicates that alcohol oxidation is probably not rate limiting in the overall reaction since normal isotope effects have been measured for alcohol oxidation reactions under similar conditions. ${ }^{12 \mathrm{a}, 25}$ It is plausible that the isotope effect originates in the equilibrium shown in Scheme 3. The relative equilibrium positions should depend on the differences in energy between $\mathrm{Pd}-\mathrm{D} / \mathrm{C}-\mathrm{D}$ as compared to the $\mathrm{Pd}-\mathrm{H} / \mathrm{C}-\mathrm{H}$ bond strength. ${ }^{26}$ This could result in the equilibrium for the Pd-D lying further on the side of the $\mathrm{Pd}-\pi$-benzyl complex. This would provide a higher concentration of the $\mathrm{Pd} \pi$-benzyl complex and thus potentially accelerate the reaction, leading to an inverse equilibrium isotope effect.

\section{Analysis of Alcohol Oxidation and Role of Metals}

Having confirmed that alcohol oxidation is the source of the Pd hydride, we wanted to determine how many equivalents of alcohol were oxidized per equivalent of styrene converted. For these experiments, a heavier alcohol was selected, namely, 2-octanol, which shows similar results to $i \mathrm{PrOH}$, for ease of detection by GC. Upon performing the experiment, it was found that 1.1 equiv of 2-octanone was formed per equivalent of styrene consumed. This confirmed our initial hypothesis that the rates of alcohol oxidation and alkene insertion/nucleophilic attack should be well-matched to achieve an efficient reaction. As an additional control to determine the role of the metal catalysts, 2-octanol was submitted to the reaction conditions omitting either Pd or Cu. Unfortunately, no alcohol oxidation occurred under those conditions, indicating that both metals were required for this transformation. It is likely that $\mathrm{Cu}^{\mathrm{II}}(\mathrm{Cu}(\mathrm{bc})$ $\mathrm{Cl}_{2}$ and/or $\mathrm{CuCl}_{2}$ ) is acting as a cooxidant for $\mathrm{Pd}^{0}$, as it does, for example, in Wacker oxidations. 18 The role of each metal in the subsequent olefin functionalization could not be tested since the Pd hydride required for the reaction was not formed in the absence of either. It seems logical, however, that $\mathrm{CuCl}_{2}$ and/or $\mathrm{Cu}(\mathrm{bc}) \mathrm{Cl}_{2}$ is acting as a chloride source to form benzylic chloride 10. To test this, and potentially distinguish the roles of the two $\mathrm{Cu}$ species, $\mathrm{CuCl}_{2}$ and $\mathrm{Cu}(\mathrm{bc})$ $\mathrm{Cl}_{2}$ were separately substituted by $\mathrm{Bu}_{4} \mathrm{NCl} .{ }^{17} \mathrm{In}$ both cases, mainly the product of a Wacker oxidation is observed (9), indicating that neither $\mathrm{CuCl}_{2}$ nor $\mathrm{Cu}(\mathrm{bc}) \mathrm{Cl}_{2}$ can simply be replaced by other chloride sources. The specific roles of ligated and nonligated $\mathrm{CuCl}_{2}$ unfortunately cannot be distinguished at this point.

\section{Proposed Mechanism}

On the basis of the information obtained from the isotopic labeling experiments, the observation of the chloride intermediate, and the other experiments shown previously, the mechanism shown in Figure 6 is proposed. Initially, Pd hydride $\mathbf{N}$ is formed via an alcohol oxidation, which 
is supported by the isotopic labeling experiments as well as the observed oxidation of 2-octanol. The styrene substrate is then coordinated to Pd, followed by insertion of the double bond into the Pd hydride. The observed incorporation of deuterium into the styrene indicates both the coordination and the insertion steps are reversible. On the basis of the observation of the primary chloride byproduct with electron-poor styrenes, it is assumed that both $\mathrm{Pd}$ alkyls $\mathbf{P}$ and $\mathbf{Q}$ are formed, as observed in the hydroalkoxylation of vinylphenols. However, $\mathbf{Q}$ can be stabilized via a $\pi$-benzyl intermediate and thus is likely formed predominantly. In the following step, chlorides $\mathbf{1 0}$ and $\mathbf{2 0}$ are formed, either via reductive elimination or nucleophilic attack on $\mathbf{P}$ or $\mathbf{Q}$, respectively, by an exogenous chloride ion. ${ }^{27}$ In either case, $\mathrm{Pd}^{\mathrm{II}}$ is reduced to a $\mathrm{Pd}^{0}$ species $(\mathbf{R})$, which is subsequently reoxidized by $\mathrm{O}_{2}$ and/or $\mathrm{CuCl}_{2}$. Additionally, $\mathrm{H}_{2} \mathrm{O}_{2}$ (formed in situ) has been shown to be a competent oxidant to form $\mathrm{Pd}^{\mathrm{IV}}$ intermediates, ${ }^{30}$ and reductive elimination of $\mathrm{C}-\mathrm{Cl}$ bonds from $\mathrm{Pd}^{\mathrm{IV}}$ has been observed previously. ${ }^{31}$ In the case of electronrich aromatic systems, the benzylic chloride is transformed into the ether product $\mathbf{8}$ via a metal promoted $\mathrm{S}_{\mathrm{N}} 1$ reaction, while in the case of more electron-poor aromatic substrates, the rate of this step is slow enough to allow for isolation of the chloride. A competing mechanism involving direct substitution of $\mathrm{Pd}$ by $i \mathrm{PrOH}$ as proposed in Figure 1B cannot be ruled out at this time. However, on the basis of the isolation of the chloride product from electron-poor styrenes and the time course showing its conversion to the hydroalkoxylation product, the mechanism shown in Figure 6 is proposed to be dominant.

\section{Conclusion}

In this paper, the development of Pd-catalyzed hydrohalogenation of styrenes, followed by a substrate dependent in situ $\mathrm{S}_{\mathrm{N}} 1$ reaction to form benzylic ethers, is disclosed. On the basis of isotopic labeling experiments, the proton incorporated into the substrate is proposed to originate from a Pd hydride formed via a Pd-catalyzed aerobic alcohol oxidation. The most exciting aspect of this transformation is this unique mechanistic motif, which contrasts with the typical use of acidic conditions in many other hydrofunctionalization reactions of olefins. Therefore, future efforts to develop new olefin hydrofunctionalization reactions in our laboratory will seek to expand the concept of coupling Pd-catalyzed aerobic alcohol oxidations.

\section{Experimental Procedures}

\section{General Information}

DCE was distilled from $\mathrm{CaH}_{2}$, and $i \mathrm{PrOH}$ was dried by refluxing over $\mathrm{CaO}$ for $12 \mathrm{~h}$ followed by fractional distillation. Styrene substrates were purified by passing through a small plug of activated neutral alumina before use. The $3 \AA$ molecular sieves were powdered and activated by heating with a Bunsen burner under vacuum. ${ }^{1} \mathrm{H}$ NMR spectra were obtained at $300 \mathrm{MHz}$ and referenced to the residual $\mathrm{CHCl}_{3}$ singlet at $7.26 \mathrm{ppm} .{ }^{13} \mathrm{C}$ NMR were obtained at $75 \mathrm{MHz}$ and referenced to the center line of the $\mathrm{CDCl}_{3}$ triplet at $77.23 \mathrm{ppm}$. Flash column chromatography was performed using EM Reagent silica 60 (230-400 mesh). GC/MS spectra were obtained on a HP 5890 (EI) 20:1 split. HRMS spectra were obtained on an Agilent LCTOF. Caution should be taken when heating flammable solvents in the presence of $\mathrm{O}_{2}$.

\section{General Procedure for Hydroalkoxylation of Electron-Rich Styrenes (8a)}

Into an oven-dried $100 \mathrm{~mL}$ Schlenk flask equipped with a stirbar were added $13.0 \mathrm{mg}$ of Pd $(\mathrm{MeCN})_{2} \mathrm{Cl}_{2}\left(0.0500 \mathrm{mmol}, 0.0500\right.$ equiv), $24.7 \mathrm{mg}$ of $\mathrm{Cu}(\mathrm{bc}) \mathrm{Cl}_{2}(0.0500 \mathrm{mmol}, 0.0500$ equiv), $26.8 \mathrm{mg}$ of $\mathrm{CuCl}_{2}(0.200 \mathrm{mmol}, 0.200$ equiv), and $500 \mathrm{mg}$ of freshly activated crushed 3 A molecular sieves. A condenser was placed on the flask, and the joint was lightly greased and wrapped with Teflon tape to ensure a good seal. DCE $(18.0 \mathrm{~mL})$ followed by $i \operatorname{PrOH}(2.00$ $\mathrm{mL}$ ) was added, and a three-way adapter fitted with a balloon of $\mathrm{O}_{2}$ was placed on the condenser. The flask was evacuated via water aspiration and refilled with $\mathrm{O}_{2} 3$ times while 
being stirred. The orange mixture was then stirred under $\mathrm{O}_{2}$ at room temperature for $30 \mathrm{~min}$, and $118 \mathrm{mg}$ of 4-methylstyrene ( $7 \mathbf{a}, 1.00 \mathrm{mmol}, 1.00$ equiv) was added via syringe. The reaction mixture was placed in an oil bath at $60{ }^{\circ} \mathrm{C}$ and stirred under $\mathrm{O}_{2}$ for $24 \mathrm{~h}$. During this time, the mixture turned from orange to brown and back to orange. After $24 \mathrm{~h}$, the mixture was cooled to room temperature and passed through a large plug of silica (ca. $8 \mathrm{~g}$ ) with $100 \mathrm{~mL}$ of $1: 1$ $\mathrm{Et}_{2} \mathrm{O} /$ hexanes. The solvent was removed in vacuo to obtain an orange oil. This was mixed with $10.0 \mathrm{~mL}$ of hexanes and washed with saturated aqueous $\mathrm{NaHCO}_{3}(3 \times 10.0 \mathrm{~mL})$. The combined aqueous layer was then extracted with hexanes $(2 \times 10.0 \mathrm{~mL})$. The combined organic layers were dried over $\mathrm{MgSO}_{4}$, and the solvent was removed in vacuo. The resulting pale yellow oil was purified via flash column chromatography by eluting with hexanes $\rightarrow 1 \% \mathrm{Et}_{2} \mathrm{O} /$ hexanes $\rightarrow 3 \% \mathrm{Et}_{2} \mathrm{O} /$ hexanes. The product $(\mathbf{8 a})$ was obtained as a clear oil $(98.4 \mathrm{mg}, 0.552 \mathrm{mmol}, 55 \%$ yield). ${ }^{1} \mathrm{H}$ NMR $\left(300 \mathrm{MHz}, \mathrm{CDCl}_{3}\right) \delta 1.09(\mathrm{~d}, J=6.3 \mathrm{~Hz}, 3 \mathrm{H}), 1.14(\mathrm{~d}, J=6.0 \mathrm{~Hz}, 3 \mathrm{H}), 1.39$ $(\mathrm{d}, J=6.3 \mathrm{~Hz}, 3 \mathrm{H}), 2.34(\mathrm{~s}, 3 \mathrm{H}), 3.48(\mathrm{qq}, J=6.0 \mathrm{~Hz}, 6.3 \mathrm{~Hz}, 1 \mathrm{H}), 4.50(\mathrm{q}, J=6.3 \mathrm{~Hz}, 1 \mathrm{H})$, $7.12-7.24(\mathrm{~m}, 4 \mathrm{H}) ;{ }^{13} \mathrm{C}$ NMR $\left\{{ }^{1} \mathrm{H}\right\}\left(75 \mathrm{MHz}, \mathrm{CDCl}_{3}\right) \delta 21.3,21.5,23.6,25.0,68.5,74.6$, 126.2, 129.2, 137.0, 142.0; MS (ESI/APCI) $\mathrm{m} / z\left(\mathrm{MNH}_{4}{ }^{+}\right)$calcd: 196.1701; obsd: 196.1693.

\section{General Procedure for Hydrochlorination of Electron-Poor Styrenes (10e)}

Into an oven-dried $100 \mathrm{~mL}$ Schlenk flask equipped with a stirbar were added $25.9 \mathrm{mg}$ of Pd $(\mathrm{MeCN})_{2} \mathrm{Cl}_{2}$ ( $0.100 \mathrm{mmol}, 0.100$ equiv), $49.5 \mathrm{mg}$ of $\mathrm{Cu}(\mathrm{bc}) \mathrm{Cl}_{2}$ ( $0.100 \mathrm{mmol}, 0.100$ equiv), $67.1 \mathrm{mg}$ of $\mathrm{CuCl}_{2}(0.500 \mathrm{mmol}, 0.500$ equiv), and $1.00 \mathrm{~g}$ of freshly activated crushed $3 \AA$ molecular sieves. A condenser was placed on the flask, and the joint was lightly greased and wrapped with Teflon tape to ensure a good seal. DCE $(19.5 \mathrm{~mL})$ followed by $i \operatorname{PrOH}(0.500$ $\mathrm{mL}$ ) was added, and a three-way adapter fitted with a balloon of $\mathrm{O}_{2}$ was placed on the condenser. The flask was evacuated via water aspiration and refilled with $\mathrm{O}_{2} 3$ times while stirring. The orange mixture was then stirred under $\mathrm{O}_{2}$ at room temperature for $30 \mathrm{~min}$. A total of $139 \mathrm{mg}$ of 4-chlorostyrene ( $1.00 \mathrm{mmol}, 1.00$ equiv) was then added via syringe, and the reaction mixture was placed in an oil bath at $50{ }^{\circ} \mathrm{C}$. The reaction mixture was stirred under $\mathrm{O}_{2}$ for $28 \mathrm{~h}$. During this time, the mixture turned from orange to dark brown. After $28 \mathrm{~h}$, the mixture was cooled to room temperature and passed through a large plug of silica (ca. $8 \mathrm{~g}$ ) with $100 \mathrm{~mL}$ of 1:1 Et $2 \mathrm{O} /$ hexanes. The solvent was removed in vacuo to obtain a clear oil. The oil was purified by flash column chromatography by eluting with hexanes $\rightarrow 1 \% \mathrm{Et}_{2} \mathrm{O} /$ hexanes $\rightarrow 5 \% \mathrm{Et}_{2} \mathrm{O} /$ hexanes $\rightarrow 10 \% \mathrm{Et}_{2} \mathrm{O} /$ hexanes. The product $(\mathbf{1 0 e})$ was obtained as a clear oil ( 60.8 $\mathrm{mg}, 0.347 \mathrm{mmol}, 35 \%$ yield; containing $6 \%$ primary chloride by NMR). ${ }^{1} \mathrm{H}$ NMR (300 MHz, $\left.\mathrm{CDCl}_{3}\right) \delta 1.83(\mathrm{~d}, J=6.87 \mathrm{~Hz}, 3 \mathrm{H}), 3.04(\mathrm{t}, J=7.42 \mathrm{~Hz}, 0.12 \mathrm{H}), 3.70(\mathrm{t}, J=7.42 \mathrm{~Hz}, 0.13$ $\mathrm{H}), 5.06(\mathrm{q}, J=6.87,1 \mathrm{H}), 7.30-7.38(\mathrm{~m}, 4 \mathrm{H}) ;{ }^{13} \mathrm{C} \mathrm{NMR}\left\{{ }^{1} \mathrm{H}\right\}\left(75 \mathrm{MHz}, \mathrm{CDCl}_{3}\right) \delta 26.7,58.0$, 128.1, 129.0, 134.2, 141.5; GC/MS: $(\mathrm{m} / \mathrm{z})$ calcd: 174.00; obsd: $173.90[\mathrm{M}]^{+}, 139.00[\mathrm{M}-$ $\mathrm{Cl}]^{+}$.

\section{Acknowledgment}

This work was supported by the National Institutes of Health (NIGMS RO1 GM3540). M.S.S. thanks the Dreyfus Foundation (Teacher-Scholar) and Pfizer for their support. We are grateful to Johnson Matthey for the gift of various Pd salts. We thank Keith M. Gligorich for useful discussions and initial experiments.

\section{References}

1. Smith, MB.; March, J. March's Advanced Organic Chemistry. John Wiley and Sons; New York: 2001.

2. a Weiss HM, Touchette KM. J. Chem. Soc., Perkin Trans. 2 1998:1517. b Sheldrake HM, Jamieson C, Burton JW. Angew. Chem., Int. Ed 2006;45:7199.

3. a Yadav VK, Babu KG. Eur. J. Org. Chem 2005:452. b Shimizu M, Toyoda T, Baba T. Synlett 2005:2516.

4. a Yang C-G, He C. J. Am. Chem. Soc 2005;127:6966. [PubMed: 15884936] b Oe Y, Ohta T, Ito Y. Chem. Commun 2004:1620. c Oe Y, Ohta T, Ito Y. Synlett 2005:179. d Coulombel L, Favier I, Dunach 
E. Chem. Commun 2005:2286. e Komeyama K, Morimoto T, Nakayama Y, Takaki K. Tetrahedron Lett 2007;48:3259. f Yang C-G, Reich NW, Shi Z, He C. Org. Lett 2005;7:4553. [PubMed: 16209477] g Taylor JG, Whittall N, Hii KK. Chem. Commun 2005:5103. h Matsukawa Y, Mizukado J, Quan H, Tamura M, Sekiya A. Angew. Chem., Int. Ed 2005;44:1138. i Hosokawa T, Shinohara T, Ooka Y, Murahashi S. Chem. Lett 1989:2001. j Munro-Leighton C, Delp SA, Blue ED, Gunnoe TB. Organometallics 2007;26:1483.

5. For examples of hydroalkoxylation reactions not requiring a triflate counterion, see:aQian $H$, Han X, Widenhoefer RA. J. Am. Chem. Soc 2004;126:9536. [PubMed: 15291546]bUtsunomiya M, Kawatsura M, Hartwig JF. Angew. Chem., Int. Ed 2003;42:5865.

6. a Rosenfeld DC, Shekhar S, Takemiya A, Utsunomiya M, Hartwig JF. Org. Lett 2006;8:4179. [PubMed: 16956181] b Li Z, Zhang J, Brouwer C, Yang C-G, Reich NW, He C. Org. Lett 2006;8:4175. [PubMed: 16956180]

7. a Coulombel L, Duñach E. Green Chem 2004;6:499. b Li Z, Zhang J, Brouwer C, Yang C-G, Reich NW, He C. Org. Lett 2006;8:4175. [PubMed: 16956180]

8. a Gligorich KM, Schultz MJ, Sigman MS. J. Am. Chem. Soc 2006;128:2794. [PubMed: 16506746] b Zhang Y, Sigman MS. Org. Lett 2006;8:5557. [PubMed: 17107071]

9. Sigman MS, Jensen DR. Acc. Chem. Res 2006;39:221. [PubMed: 16548511]

10. Tsuchiya Y, Hamashima Y, Sodeoka M. Org. Lett 2006;8:4851. [PubMed: 17020319]

11. Balija AM, Stowers KJ, Schultz MJ, Sigman MS. Org. Lett 2006;8:1121. [PubMed: 16524283]

12. aten Brink G-J, Arends IWCE, Sheldon RA. Adv. Synth. Catal 2002;344:355. For aerobic Pdcatalyzed oxidations of longer chain alcohols, see: bSchultz MJ, Hamilton SS, Jensen DR, Sigman MS. J. Org. Chem 2005;70:3343. [PubMed: 15844968]

13. a Johns AM, Utsunomiya M, Incarvito CD, Hartwig JF. J. Am. Chem. Soc 2006;128:1828. [PubMed: 16464081] b Johns AM, Tye JW, Hartwig JF. J. Am. Chem. Soc 2006;128:16010. [PubMed: 17165734]

14. Nishimura T, Kakiuchi N, Onoue T, Ohe K, Uemura S. J. Chem. Soc., Perkin Trans. 1 2000:1915. 15. A similar induction period was observed with $\mathrm{Pd}[(-)$-sparteine $]-\mathrm{Cl}_{2}$ (see Supporting Information).

16. a Allan JR, Paton AD, Turvey K, Bowley HJ, Gerrard DL. J. Coord. Chem 1989;19:303. b Enquist P-A, Lindh J, Nilsson P, Larhed M. Green Chem 2006;8:338.

17. See Supporting Information.

18. Tsuji, J. Palladium Reagents and Catalysts. John Wiley and Sons; New York: 1995. b Cornell CN, Sigman MS. Inorg. Chem 2007;46:1903. [PubMed: 17348721]

19. Mueller JA, Cowell A, Chandler BD, Sigman MS. J. Am. Chem. Soc 2005;127:14817. [PubMed: 16231935]

20. It is also possible that the ratio of $\mathrm{K}$ and $\mathrm{L}$ is affected by the electronics of the aryl ring via different stabilization of the $\pi$-benzyl complex (see ref 21).

21. van Asselt R, Vrieze K, Elsevier CJ. J. Organomet. Chem 1994;480:27.

22. a Reetz MT, Sauerwald M, Walz P. Tetrahedron Lett 1981;22:1101. b Dau-Schmidt J-P, Mayr H. Chem. Ber 1993;127:205. c Pock R, Klein H, Mayr H. Chem. Ber 1986;119:929. d Mayr H, Schade C, Rubow M, Schneider R. Angew. Chem., Int. Ed. Engl 1987;26:1029.

23. For a proposed mechanism of a Pd-catalyzed H/D exchange via the enol form of acetone, see: Portnoy M, Milstein D. Organometallics 1994;13:600.

24. D incorporation into styrene could not be quantified due to the loss of $H(D)$ in the mass spectrometer. Additionally, different product ratios were observed for reactions involving deuterated alcohol and/ or styrene, and deuterium incorporation was observed in the Wacker product, which should originate from deuterated styrene.

25. Mueller JA, Sigman MS. J. Am. Chem. Soc 2003;125:7005. [PubMed: 12783555]

26. Anslyn, EV.; Dougherty, DA. Modern Physical Organic Chemistry. University Science Books; Sausalito, CA: 2006.

27. Nucleophilic attack on Pd ${ }^{\mathrm{II}}$-allyl and $\pi$-benzyl complexes has been proposed by Hartwig et al.13 and Bäckvall et al.,28 respectively, in related reactions. Reductive elimination of a $\mathrm{C}-\mathrm{Cl}$ bond from a $\mathrm{Pd}^{\mathrm{II}}$-alkyl complex has been proposed by Henry and Hamed.29

28. Bäckvall J-E, Nyström J-E, Nordberg RE. J. Am. Chem. Soc 1985;107:3676. 
29. Hamed O, Henry PM. Organometallics 1998;17:5184.

30. Desai LV, Malik HA, Sanford MS. Org. Lett 2006;8:1141. [PubMed: 16524288]

31. Kalyani D, Dick AR, Anani WQ, Sanford MS. Org. Lett 2006;8:2523. [PubMed: 16737304] 
๑<smiles>[R]C=[13CH][13CH3]</smiles><smiles>CCO</smiles><smiles>N#N</smiles>

1

A

R 2<smiles>CC(N)N</smiles>

\section{Mechanism for Acid Catalyzed Hydrofunctionalization Reactions.}<smiles>C=CP</smiles>

1

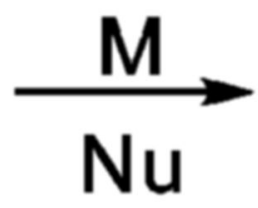

\section{Proposed Mechanism for Metal Catalyzed Hydrofunctionalization Reactions.}

Figure 1.

Proposed mechanisms for (A) acid-catalyzed and (B) metal-catalyzed hydrofunctionalizations. 
<smiles>C=Cc1ccccc1[O-]</smiles>

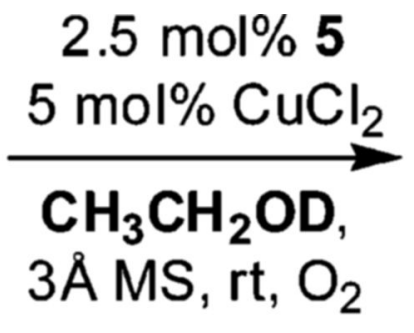<smiles>CCOC(C)c1ccccc1O</smiles>
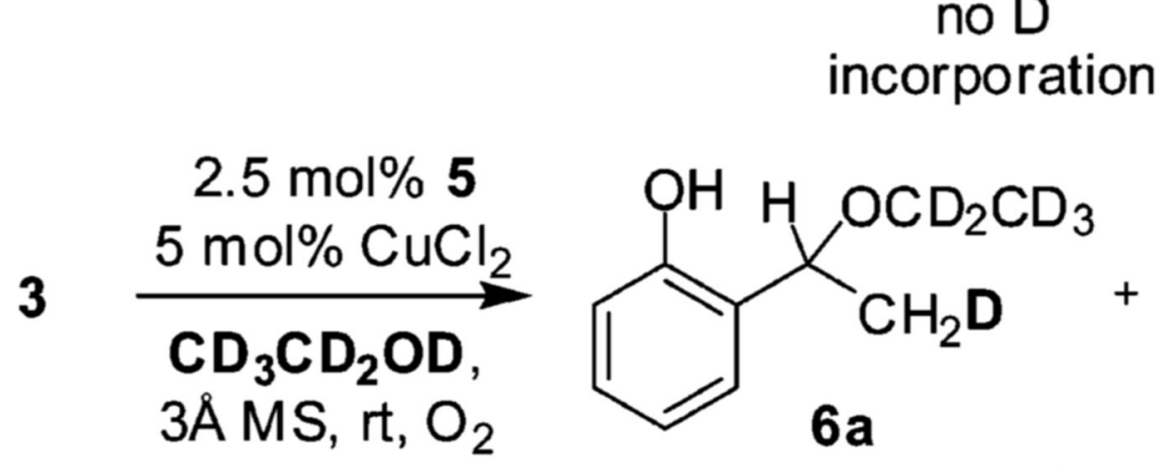<smiles>[2H]CC(OC(C)(C)C)c1ccccc1O</smiles>

$6 a$<smiles>[2H]C(C)(C)OC(C)(C)c1ccccc1O</smiles>

5: $\mathrm{Pd}[(-)$-sparteine $] \mathrm{Cl}_{2}$

$$
2.5: 1
$$

Scheme 1.

Deuterium Labeling for Hydroalkoxylation of Vinylphenols 


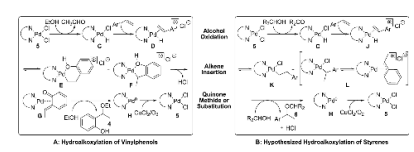

Figure 2.

Proposed mechanism for hydroalkoxylation of vinylphenols $(A)^{8 \mathrm{a}}$ and hypothesis for hydroalkoxylation of styrenes (B). 


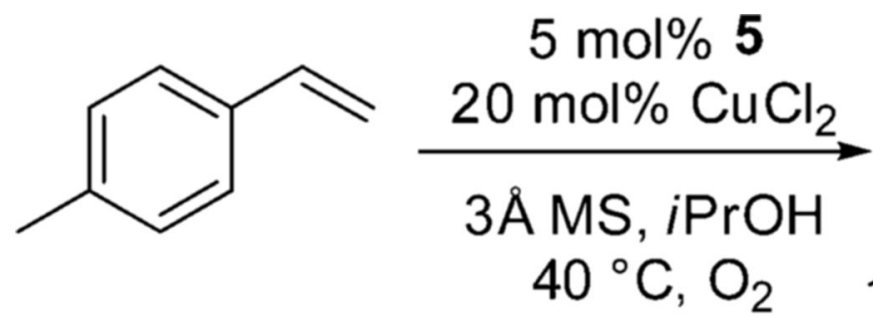

$7 a$

5: $\mathrm{Pd}[(-)$-sparteine $] \mathrm{Cl}_{2}$<smiles>Cc1ccc(C(C)O)cc1</smiles>

$8 a$<smiles>CC(=O)c1ccc(C)cc1</smiles>

$50 \%$ yield

Scheme 2.

Initial Discovery of Hydroalkoxylation of Styrenes 


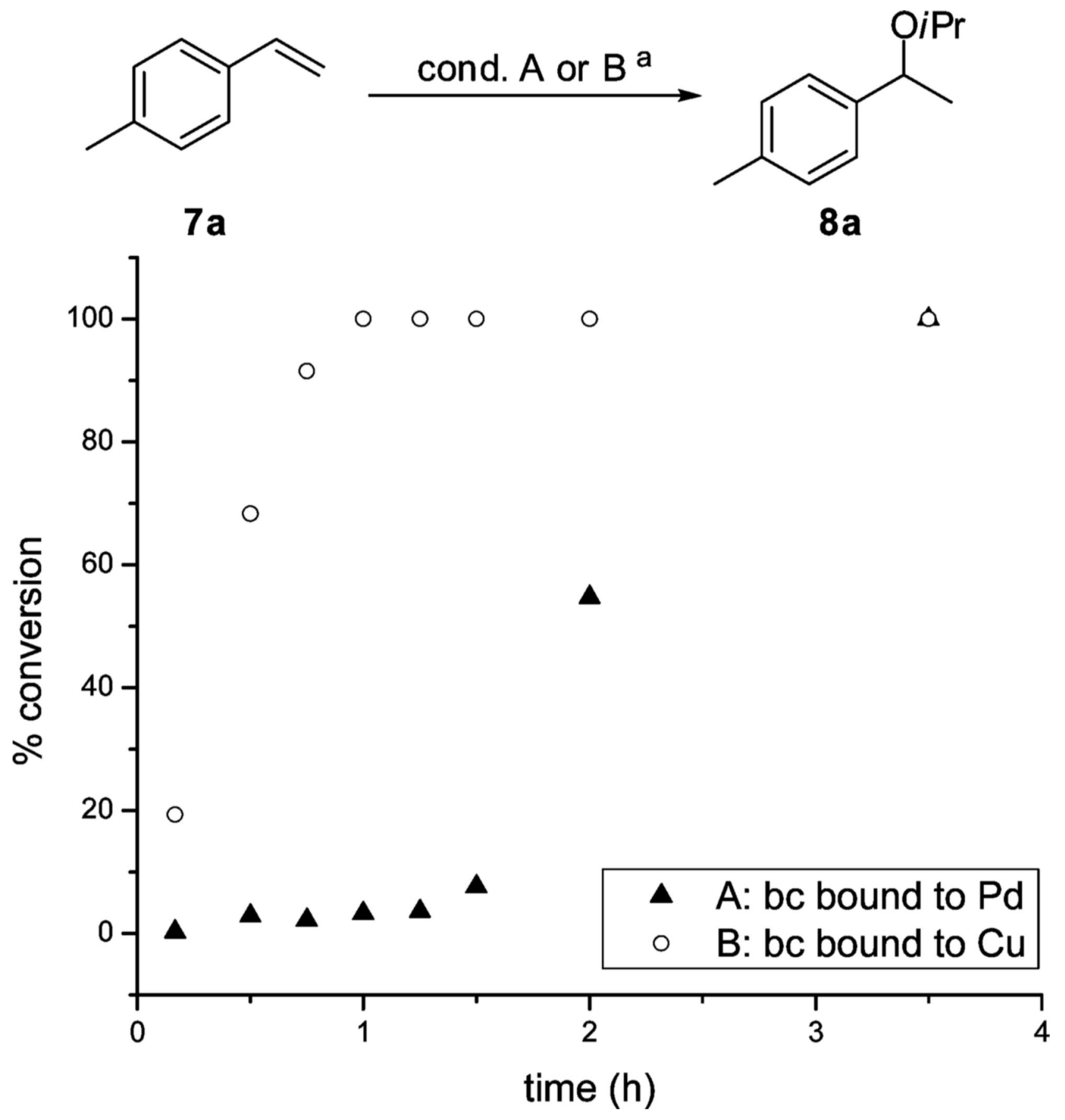

Figure 3.

Time course of hydroalkoxylation with $\mathrm{Pd}(\mathrm{bc}) \mathrm{Cl}_{2}$ and $\mathrm{Cu}(\mathrm{bc}) \mathrm{Cl}_{2} \cdot{ }^{a} \mathrm{Condition} \mathrm{A}: 10 \mathrm{~mol} \% \mathrm{Pd}$ (bc) $\mathrm{Cl}_{2}, 40 \mathrm{~mol} \% \mathrm{CuCl}_{2}, 3 \AA$ molecular sieve, $60 \%$ iPrOH/DCE, $40^{\circ} \mathrm{C}$, balloon $\mathrm{O}_{2}$. Condition B: $10 \mathrm{~mol} \% \mathrm{Pd}(\mathrm{MeCN})_{2} \mathrm{Cl}_{2}, 10 \mathrm{~mol} \% \mathrm{Cu}(\mathrm{bc}) \mathrm{Cl}_{2}, 30 \mathrm{~mol} \% \mathrm{CuCl}_{2}, 3 \AA$ molecular sieve, $60 \% i \mathrm{PrOH} / \mathrm{DCE}, 40^{\circ} \mathrm{C}$, balloon $\mathrm{O}_{2}$. 


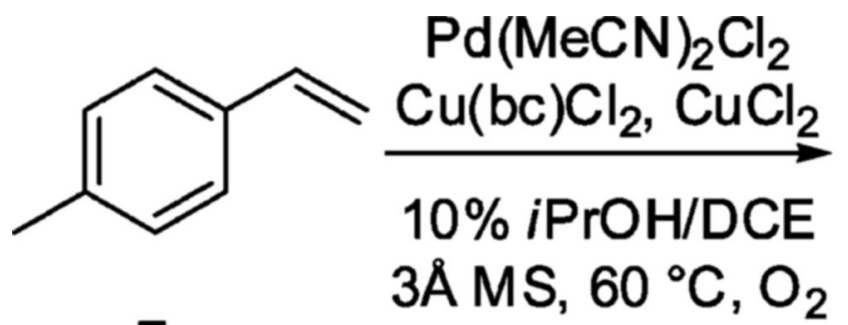

$7 a$<smiles>Cc1ccc(C(C)Cl)cc1</smiles>

- $\mathbf{\square}$

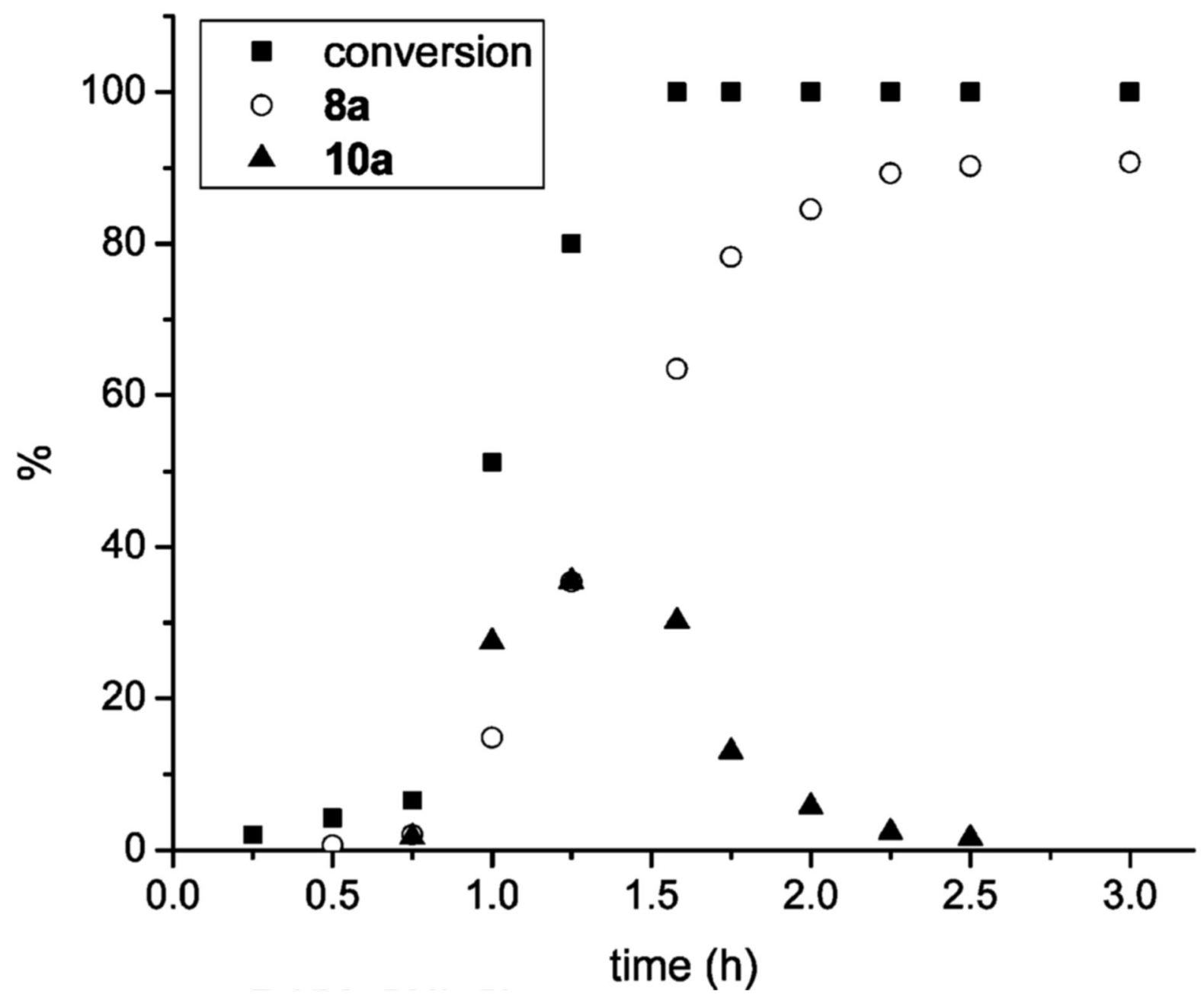<smiles>Cc1ccc(C(C)O)cc1O</smiles>

8 a

Figure 4.

Time course of hydroalkoxylation showing chloride intermediate. 


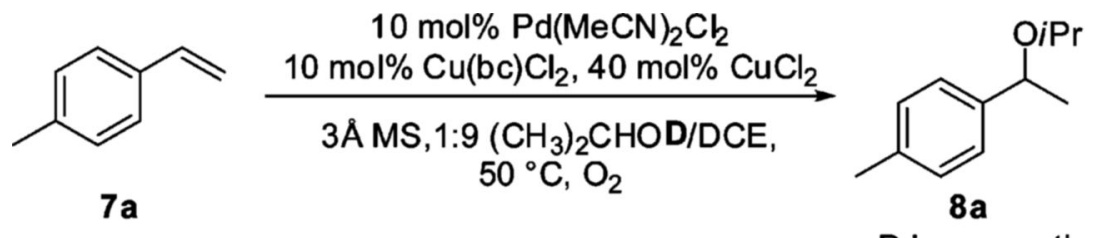

no $D$ incorporation

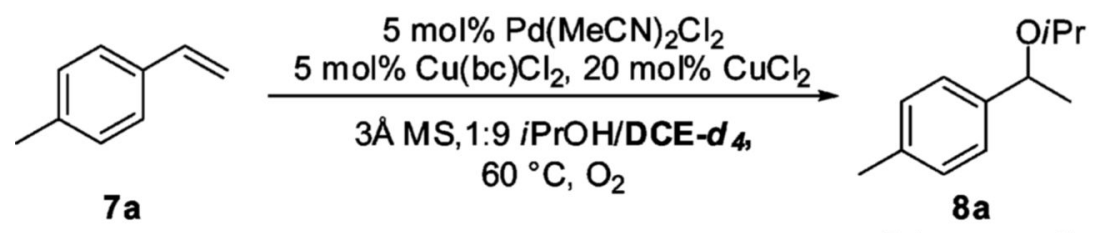

no $D$ incorporation

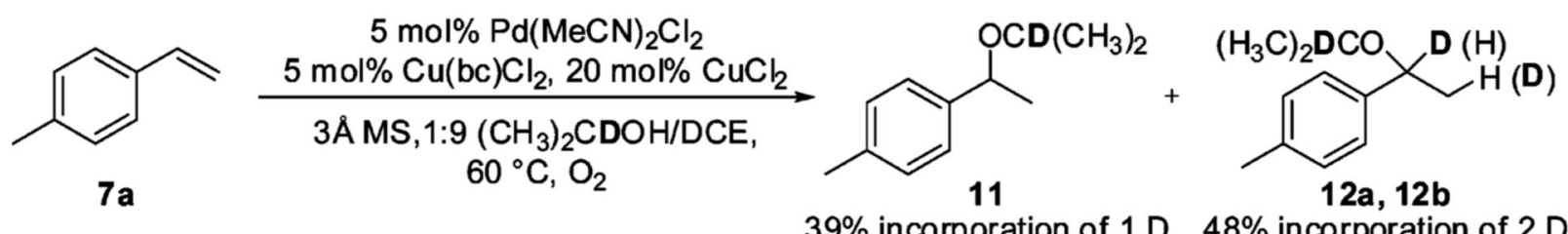

$39 \%$ incorporation of $1 \mathrm{D} \quad 48 \%$ incorporation of $2 \mathrm{D}$

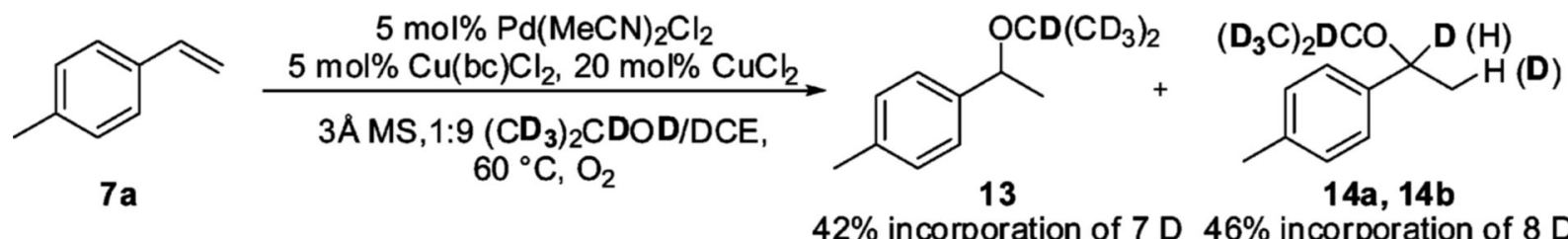

$42 \%$ incorporation of 7 D $46 \%$ incorporation of $8 \mathrm{D}$
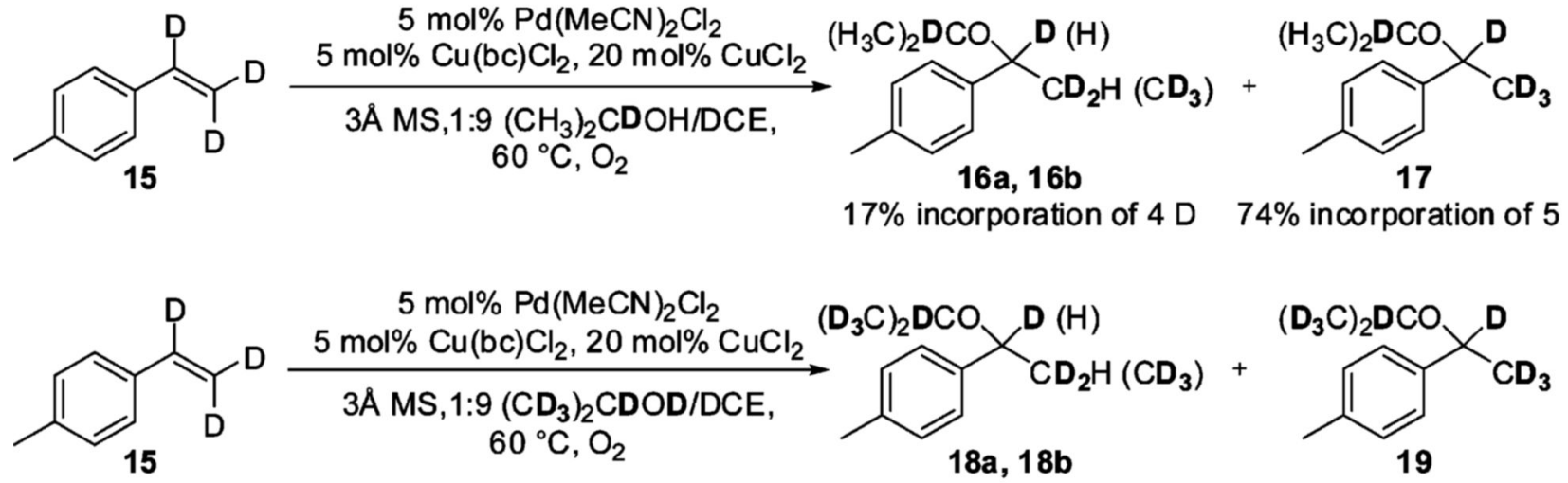<smiles>[2H]C(O)(C(=O)OCc1ccccc1)c1ccc(C)cc1</smiles>

$18 a, 18 b$

$19 \%$ incorporation of $10 \mathrm{D} \quad 81 \%$ incorporation of $11 \mathrm{D}$<smiles></smiles>

Figure 5.

Deuterium labeling studies. 


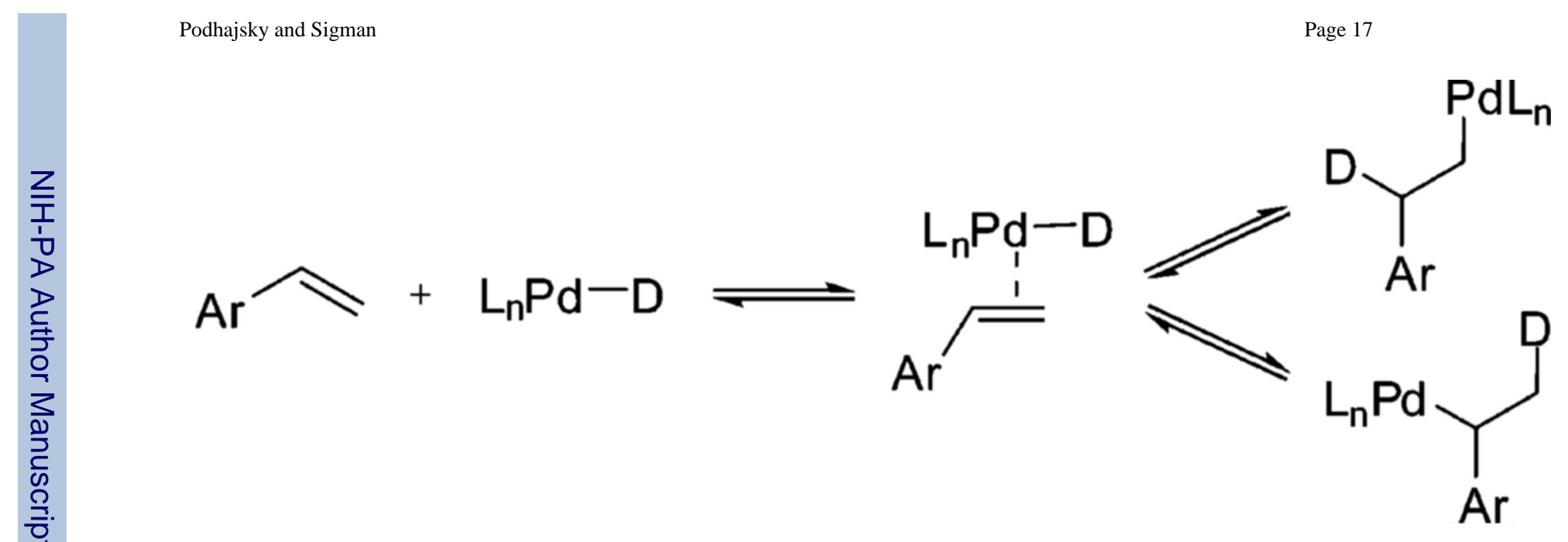

Scheme 3.

Reversible Alkene Insertion/ $\beta$-Hydride Elimination 


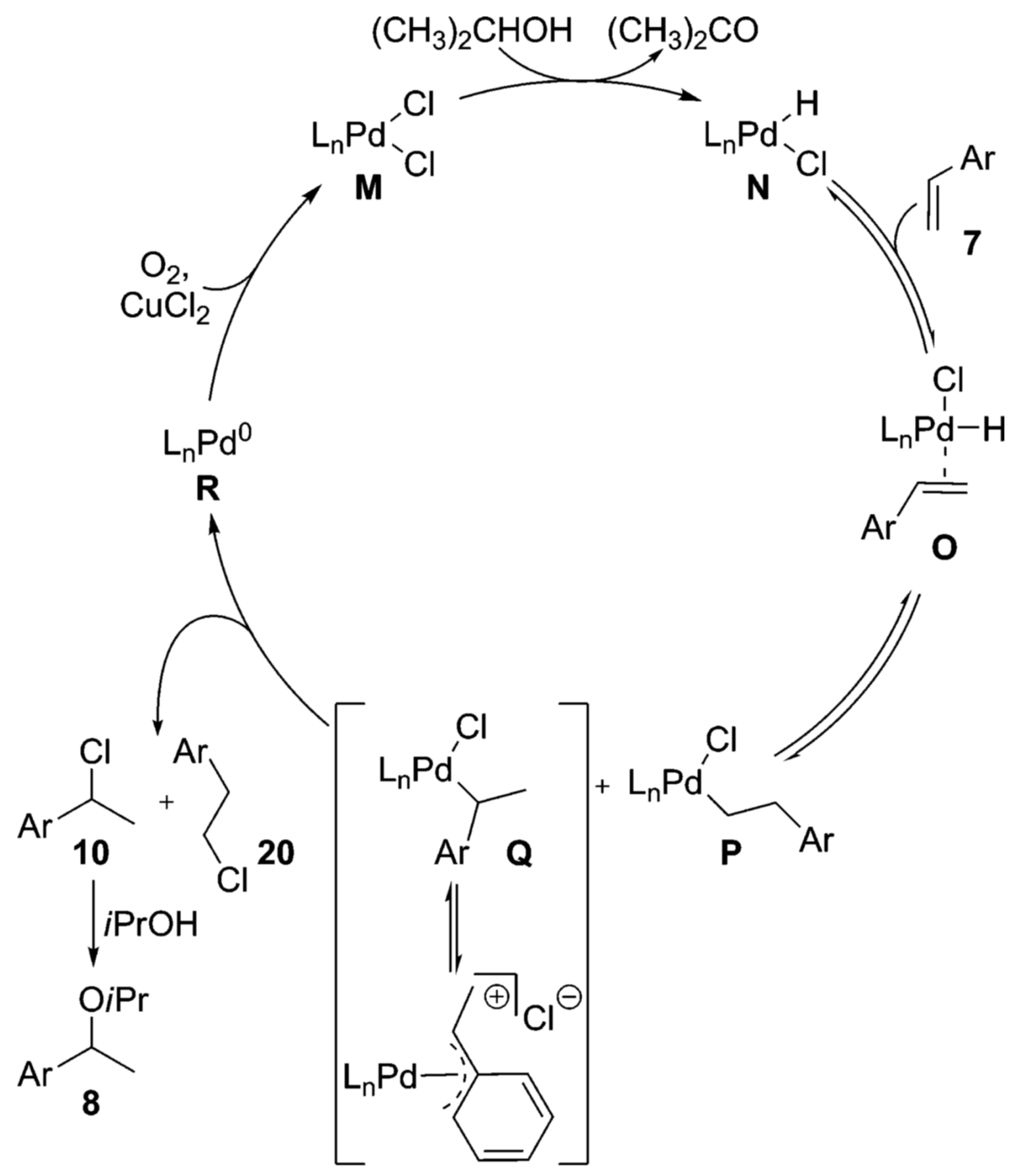

Figure 6.

Proposed mechanism of hydrohalogenation/hydroalkoxylation of styrenes. 


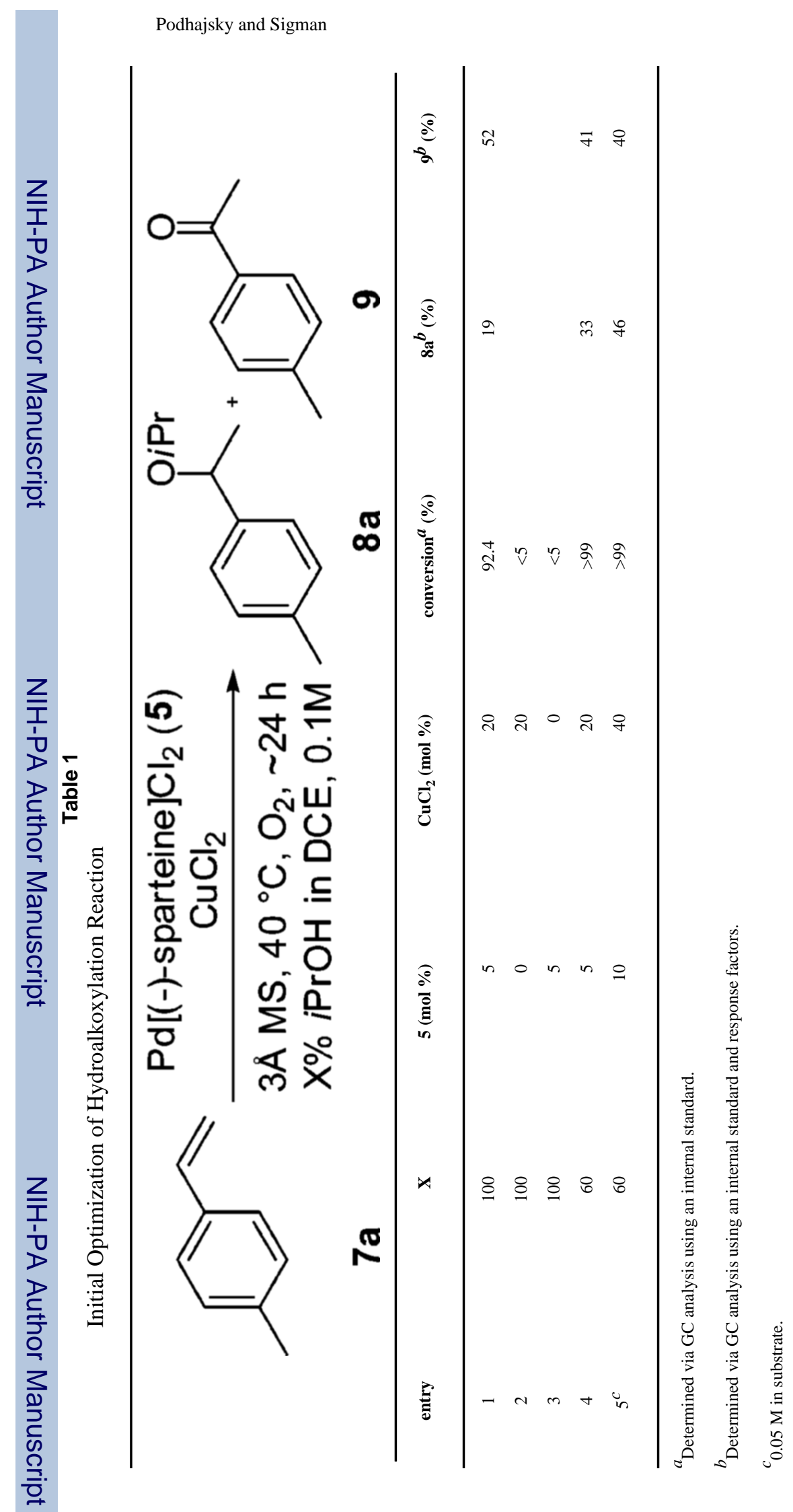

Organometallics. Author manuscript; available in PMC 2009 September 23. 


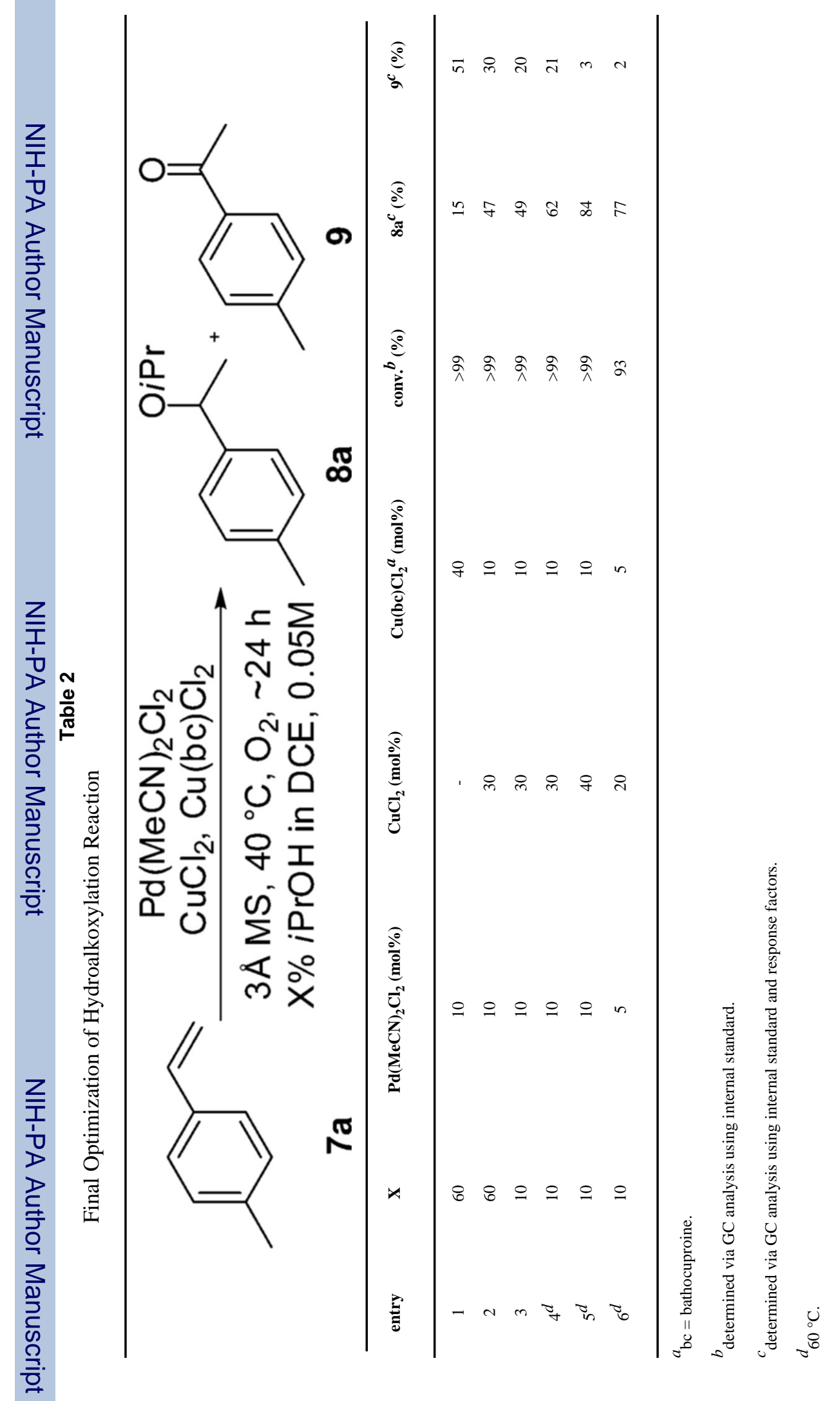




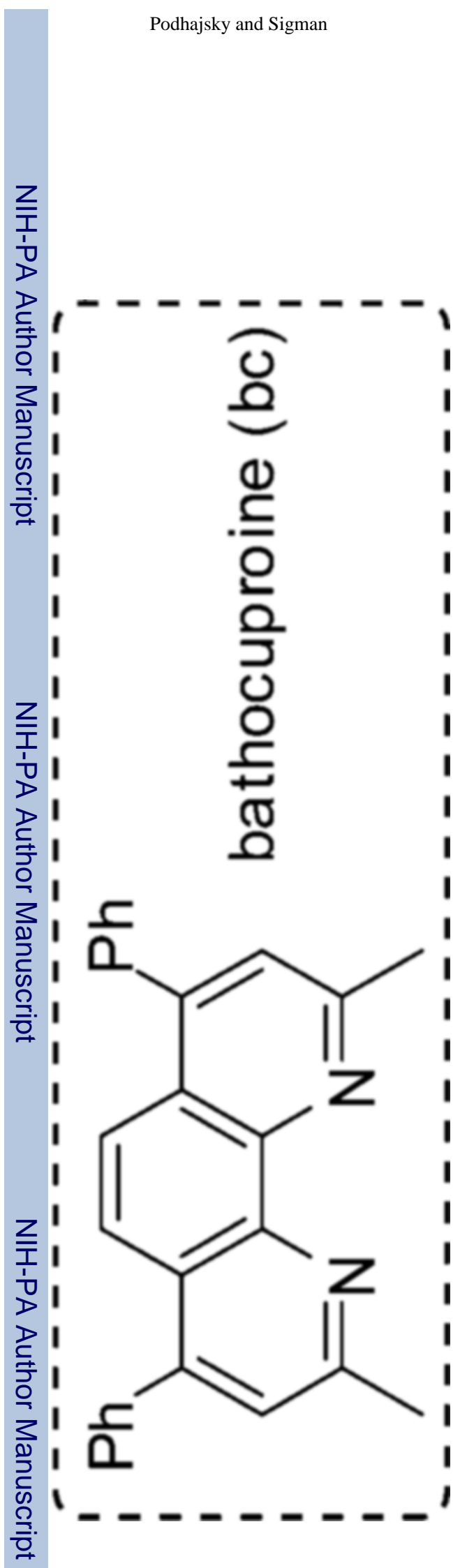

Organometallics. Author manuscript; available in PMC 2009 September 23. 
Table 3

Scope of Hydrochlorination/Hydroalkoxylation Reaction
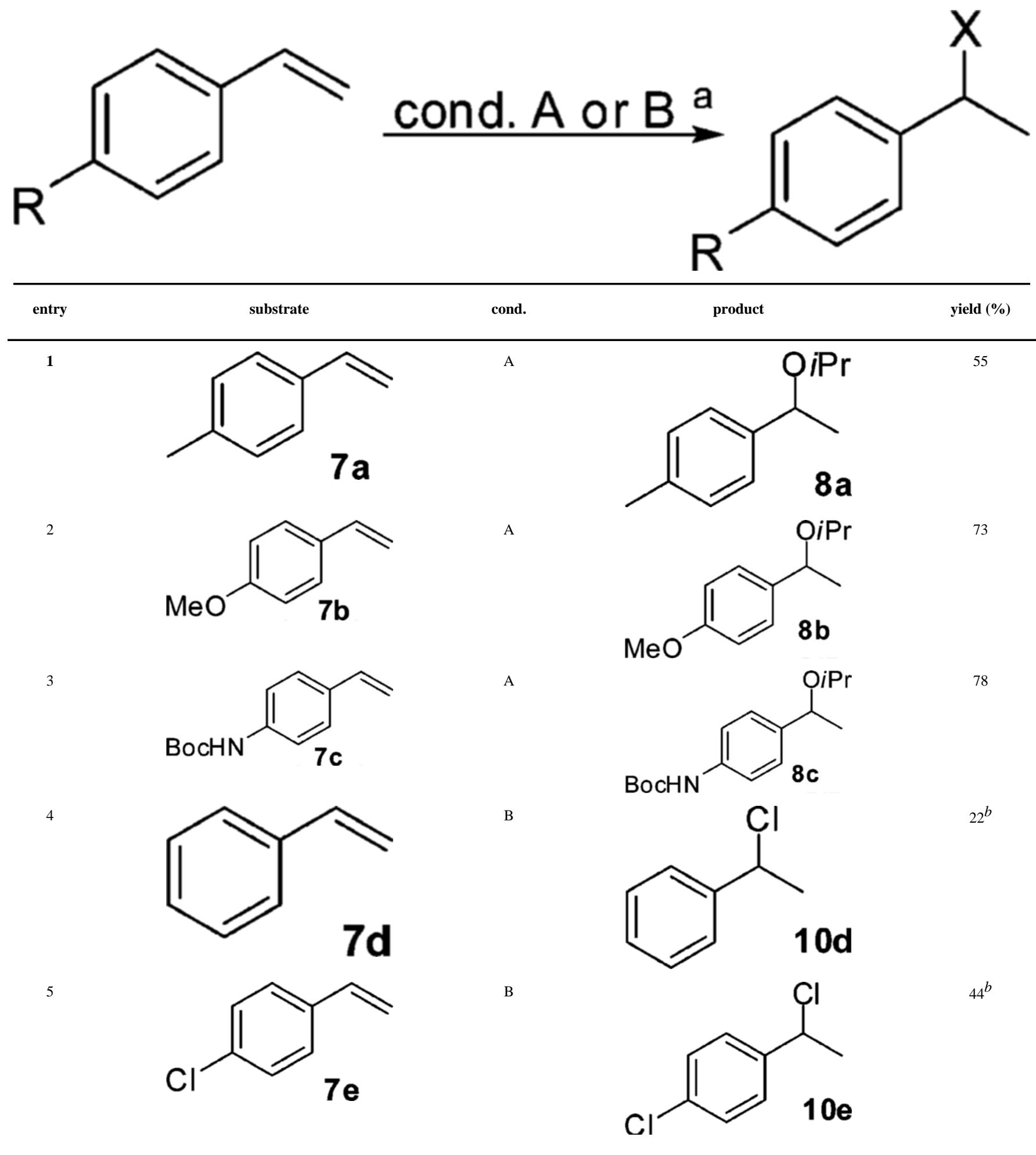

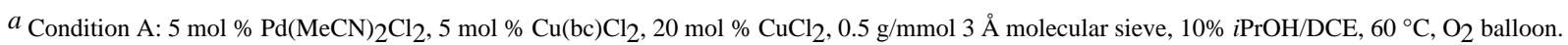
Condition B: $10 \mathrm{~mol} \% \mathrm{Pd}(\mathrm{MeCN})_{2} \mathrm{Cl}_{2}, 10 \mathrm{~mol} \% \mathrm{Cu}(\mathrm{bc}) \mathrm{Cl}_{2}, 50 \mathrm{~mol} \% \mathrm{CuCl}_{2}, 1.0 \mathrm{~g} / \mathrm{mmol} 3 \AA$ molecular sieve, $2.5 \%$ iPrOH/DCE, $50{ }^{\circ} \mathrm{C}, \mathrm{O}_{2}$ balloon. 
${ }^{b}$ Including ca. 5\% regioisomer (primary chloride). 
Table 4

Promotion of Conversion of $10 \mathrm{a}$ to $8 \mathrm{a}$ by Different Additives

\begin{tabular}{|c|c|c|c|c|}
\hline entry & additive & time (h) & $\%$ conversion $^{a}$ & $\% 8 a^{b}$ \\
\hline 1 & & 22.5 & 30 & 29 \\
\hline 2 & $\begin{array}{l}1 \mathrm{~g} / \mathrm{mmol} 3 \AA ̊ ̊ m \text { molecular } \\
\text { sieve }\end{array}$ & 22.5 & 39 & 38 \\
\hline 3 & $\begin{array}{l}10 \mathrm{~mol} \% \mathrm{Cu}(\mathrm{bc}) \mathrm{Cl}_{2}, 30 \mathrm{~mol} \\
\% \mathrm{CuCl}_{2}, 1 \mathrm{~g} / \mathrm{mmol} 3 \AA^{\circ} \\
\text { molecular sieve }\end{array}$ & 15.5 & 79 & 73 \\
\hline 4 & $\begin{array}{l}10 \mathrm{~mol} \% \mathrm{Pd}(\mathrm{MeCN})_{2} \mathrm{Cl}_{2}, 1 \\
\mathrm{~g} / \mathrm{mmol} 3 \AA \text { molecular sieve }\end{array}$ & 15.5 & 67 & 62 \\
\hline 5 & $\begin{array}{l}10 \mathrm{~mol} \% \mathrm{Cu}(\mathrm{bc}) \mathrm{Cl}_{2}, 30 \mathrm{~mol} \\
\% \mathrm{CuCl}_{2}, 10 \mathrm{~mol} \% \mathrm{Pd} \\
(\mathrm{MeCN})_{2} \mathrm{Cl}_{2}, 1 \mathrm{~g} / \mathrm{mmol} 3 \AA \\
\text { molecular sieve }\end{array}$ & 15.5 & 91 & 85 \\
\hline
\end{tabular}

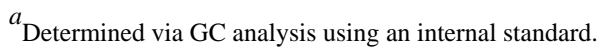

${ }^{b}$ Determined via GC analysis using an internal standard and response factors. 